\title{
Improvement of thermo-aeraulic comfort with integrated solar wall system under Saharan climate
}

\author{
Sidi Mohammed El Amine Bekkouche ${ }^{1, *}$, Tayeb Benouaz ${ }^{2}$, Rabéa Kaoulal ${ }^{3}$, Maamar Hamdani ${ }^{1}$, \\ and Mohamed Kamel Cherier ${ }^{1}$ \\ ${ }^{1}$ Unité de recherche appliquée en énergies renouvelables (URAER), centre de développement des énergies renouvelables (CDER), \\ 47133 Ghardaïa, Algeria \\ ${ }^{2}$ University of Tlemcen, BP 119, 13000 Tlemcen R.P., Algeria \\ ${ }^{3}$ Department Science of Matter, Faculty of Science and Technology, University of Adrar, Adrar, Algeria
}

\begin{abstract}
The aim of this paper is devoted to an example of a concrete application in the bioclimatic architecture: integration of a simple solar air collector in building facades under Saharan climate. The originality of this work is to lift a serious problem that is often encountered in the summer when the indoor air cooling mode through natural ventilation becomes ineffective. We showed that the specific architectural integration of solar air collectors can bring a positive support to the thermo-aeraulic comfort by controlling the mass flow rate of the air entering to the heated building zone in cold season. The major inconvenience of this technique is often encountered in summer. To ensure the reliability of this technique that is sometimes regrettable, it is first necessary to control automatically the opening and closing the air ventilation valve.
\end{abstract}

\section{Introduction}

The exploration of these solar devices is useful in various applications, we cite as an illustrative example: solar drying, heating, natural ventilation, etc. Recently, the work carried out confirms that the thermal comfort in a low energy house relies on several techniques and uses some renewable energetic resources. Christoph et al. [1] have used several techniques using simple, more accurate models and fewer complexes than detailed physical models. In references [2-4], the applications of building integrated solar thermal collectors were presented and standards for assessing thermal performance of solar thermal systems were addressed. The major features, current status and existing difficulties related to the various types of solar thermal collectors were identified.

This work consists in integrating this solar device in the southern facade of a multizone building located in Saharan city. We can, with this approach, study the Trombe wall technique. The originality of this work is to lift a serious problem that is often encountered in the summer when the indoor air cooling mode through natural ventilation becomes ineffective. This situation is encountered specifically when comfort parameters (air temperature and humidity) are outside the range of comfort interval (psychrometric diagram). Generally, these situations are marked by external temperatures, which are higher than the comfort temperature $\left(27^{\circ} \mathrm{C}\right)$ for a dry climate. The thermo-aeraulic model of

\footnotetext{
* e-mail: smabekkouche@yahoo.fr
}

building has been already validated in previous work [5-7]. For the flat plate solar collector, the heat-balance system will be coupled with the multizone model. A transient thermal model, based on the heat balances of different components has been developed. Also, the proposed model is based on the thermal nodal method [8,9], which is very widespread because it requires a reduced memory capacity; allows to have results in a relatively short time. The system of differential equations that govern the heat balances has been solved using Runge-Kutta fourth order numerical method.

\section{Description and mathematical modelling of the coupled system}

The used solar air collector (mounted on the south) is a singleglazed plate, we summarise the main components as follows: - a single transparent glass cover of dimensions 4-mm thick, transmits the heat flux to the absorber plate, ensures the reduction of thermal losses due to the heat exchange by convection and radiation and protects the absorber from the outside environment;

- a thin copper absorber plate with a black chrome finish on it, which was $1.5-\mathrm{mm}$ thick;

- a polystyrene sheet with a thickness of $40 \mathrm{~mm}$, placed alongside a wooden case to minimize the heat loss from the back and sides of the collector.

Working principle of flat plate solar air collector is given in detail in reference [10]; the air passage generates an air flow toward the principle axis represented by the $x$-axis as 


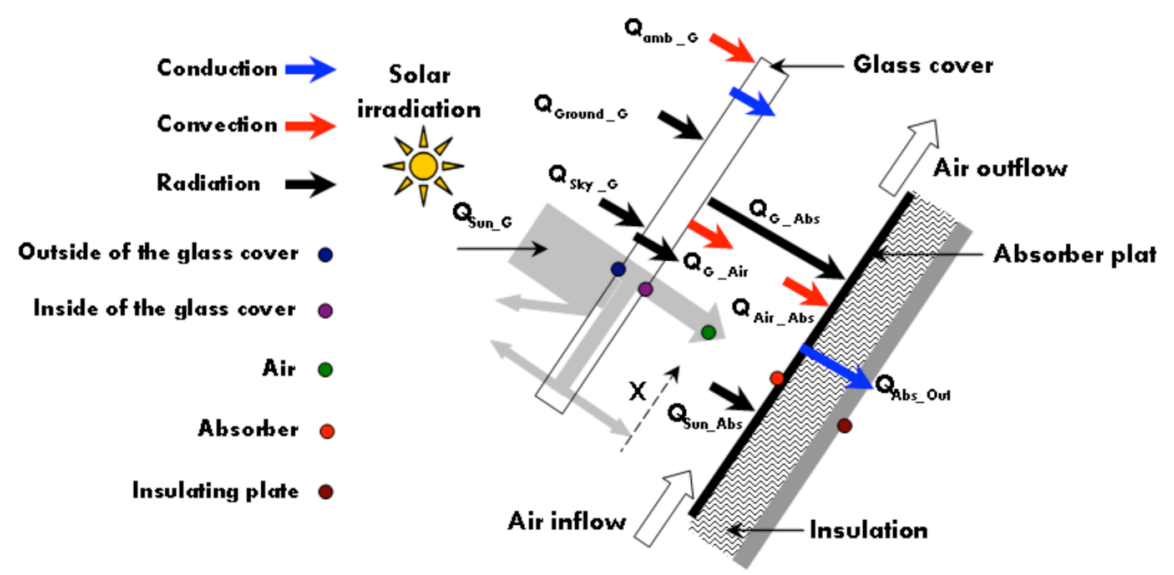

Fig. 1. Schematic view, types of nodes and heat balance of the flat plate solar collector.

shown in Figure 1 above. However, the solar system can be an effective solution for buildings, which have a problem with ventilation and heating in cold season. The use of these techniques also allows avoiding unexpected problems of humidity. In hot season, solar air collectors are used generally to dehumidify the indoor air in buildings.

The equations governing the performance of the flat plat solar air collector are formulated using the thermal balance equations. The sky is considered as a black body, thermo-physical properties of materials are assumed to be constant, the transparent glass cover is opaque to infrared radiation, the air between the single glass cover and the absorber is assumed to be transparent and finally the heat transfer is assumed to be unidirectional, in perpendicular direction to the air collector. The nodal method leads to the setting up of an electrical network. The nodes, which in an electrical meaning symbolize equipotentials, correspond to isotherm lines. On the outside of the transparent glass cover, the heat-balance equation is written as follow:

$$
\begin{aligned}
C_{G} \frac{d T_{\mathrm{G}}}{d t} & =Q_{\mathrm{Sun} \_\mathrm{G}}+Q_{\mathrm{Sky} \_\mathrm{G}}+Q_{\mathrm{Ground} \_\mathrm{G}}+Q_{\mathrm{amb} \_\mathrm{G}} \\
& -Q_{\mathrm{G} \_\mathrm{Abs}}-Q_{\mathrm{G} \_\mathrm{Air}} .
\end{aligned}
$$

$Q_{\text {Sun G }}$ : the heat flux emitted by the sun incident on the transparent glass cover.

$Q_{\mathrm{Sky}_{\mathrm{G}} \mathrm{E}}$ the heat flux emitted by the sky incident on the transparent glass cover.

$Q_{\text {Ground_G: the radiation heat transfer emitted by the }}$ ground on the transparent glass cover.

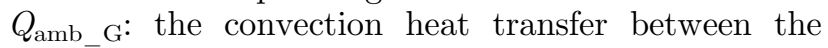
transparent glass cover and the ambient air.

$Q_{\mathrm{G}_{-} \text {Abs: }}$ the radiation heat transfer between the transparent glass cover and absorber.

$Q_{\mathrm{G} \text { Air }}$ : the heat flux, which represents the convection heat exchange between the transparent glass cover and the air. The amount of heat extracted from the control volume between $x$ and $x+d x$ is given by equation (2), thus, the heat equation for our case can be written by equation (3).

$$
\frac{d Q u}{d x^{\prime}}=\dot{m} C_{\text {air }} \frac{d T_{\text {air }}}{d x^{\prime}},
$$

$$
\dot{m} C_{\text {air }} \frac{d T_{\text {air }}}{d x^{\prime}}=Q_{\text {Gin_Air }}-Q_{\text {Air_Abs }} .
$$

$x^{\prime}=x / L$ : relative position relative to the main axis.

$Q_{\text {Air_Abs: }}$ the heat flux, which represents the convection heat exchange between the absorber and the air.

We focus our calculations on the determination of the air temperature at any position $x$. Energy balance for absorber is represented below:

$$
\begin{aligned}
C_{\mathrm{Abs}} \frac{d T_{\mathrm{Abs}}}{d t} & =Q_{\text {Sun_Abs }}+Q_{\mathrm{G}_{-} \mathrm{Abs}}+Q_{\text {Air_Abs }} \\
& -Q_{\text {Abs_Outs }} .
\end{aligned}
$$

For the multizone building modelling, temporal variations in mass are very low amounts; the change in enthalpy can be assimilated to the variation in temperature [5-7]:

$$
\begin{aligned}
\rho_{a s} C_{a s} V(i) \frac{d T_{a l}(i)}{d t} & =\sum_{i=0}^{N}\left[Q_{\text {mas }}^{\text {trans }}(i, n) C_{a s}\left(T_{a l}(n)-T_{a l}(i)\right)\right] \\
& +\sum_{j=i}^{N W(i)}\left[S_{j} h_{c i j}\left(T_{s i j}(i)-T_{a l}(i)\right)\right] \\
& +P_{s}+C I_{s} .
\end{aligned}
$$

The first term of the second expression represents the convective flow exchange between surfaces $j$ of walls for zone $i$ corresponding to a temperature $T_{s i j}$ and the air mass in this zone corresponding to a temperature $T_{a l}(\mathrm{~W})$. We obtain a system of $n$ equations with $n$ unknowns; the main variables are the air temperatures in each zone. The surface temperature $T_{s i j}$ will be obtained by establishing thermal balance of the wall inner surface. It is through these balances that we see couplings with other modes of heat transfer. With using the simplified conservation equation of the dry air mass, we get equation (6) [5-7]:

$$
\begin{aligned}
m_{a s}(i) \frac{d r_{s}(i)}{d t} & =\sum_{i=0}^{N}\left[Q_{\text {mas }}^{\text {trans }}(i, n)\left(r_{s}(n)-r_{s}(i)\right)\right]+\frac{P_{L}}{L_{v}} \\
& +\frac{C I_{L}}{L_{v}} .
\end{aligned}
$$




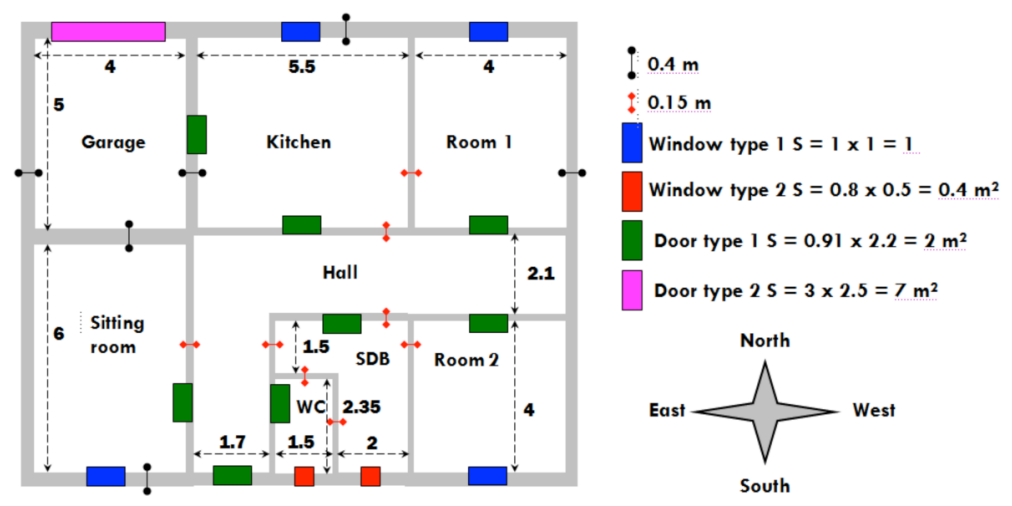

Fig. 2. Descriptive plane: southern orientation, dimensions are given by $m$.

Table 1. Layer thickness, walls composition and $U$ values for building envelope.

\begin{tabular}{llcc}
\hline & Composition & Thickness $(\mathrm{cm})$ & $\begin{array}{c}\text { Thermal transmittance } \\
\text { values } U\left(\mathrm{~W} \mathrm{~m}^{-2} \mathrm{~K}^{-1}\right)\end{array}$ \\
\hline \multirow{4}{*}{ Exterior walls } & Mortar cement & 1.5 & 1.97 \\
& Stone & 40 & \\
& Mortar cement & 1.5 & \\
& Coating plaster & 1.0 & 2.82 \\
Interior walls & Mortar cement & 1.5 & \\
& Stone & 15 & \\
& Mortar cement & 1.5 & 0.93 \\
Ground & Coating plaster & 1.0 & \\
& Tiling & 2.5 & \\
& Cement & 1 & 1.05 \\
Roof & Stone & 6 & \\
Flat glass & Concrete & 24 & 5.91 \\
\hline
\end{tabular}

As for the sensitive balance, a system of $n$ equations with $n$ unknowns is obtained; the main variables are the specific humidities in each zone. We can use the empirical formulas of Nadeau and Puiggali [11,12]; specific humidity may be expressed as a function of relative humidity by the relationship:

$$
\begin{aligned}
& H_{s}=\frac{0.622 P_{\text {sat }}(T) H r}{101325-P_{\text {sat }}(T) H r} \\
& P_{\text {sat }}(T)=e^{23.3265-\frac{380.7^{2}}{T}-\frac{472.68^{2}}{T}} .
\end{aligned}
$$

Superficial exchanges, especially convective exchanges are complex phenomena governed by the fluid mechanics laws, we will support on the proposed approaches in reference [12]. For more clarification, consult the work in the article given by reference [12].

\section{Description and mathematical modelling of the coupled system}

The study was carried out on a building in Ghardaïa, the house has an area of $149.3450 \mathrm{~m}^{2}$; wall heights are equal to $4 \mathrm{~m}$ while the other dimensions are shown in detail in Figure 2 and Table 1. The house is characterized by poor compactness, exposed to outdoor conditions at all levels. The application below is an example, which illustrates the reach level of the thermo-aeraulic comfort from 8 to 11 August 2014 in Ghardaïa site. The measured temperatures of the outside air are between 30.45 and $46.1^{\circ} \mathrm{C}$, external ambient relative humidity corresponds to values less than $31.36 \%$ (low), the sky is completely clear. We deduce our predictions by displaying the results of numerical simulations in Figures 4 and 5 following several cases. 

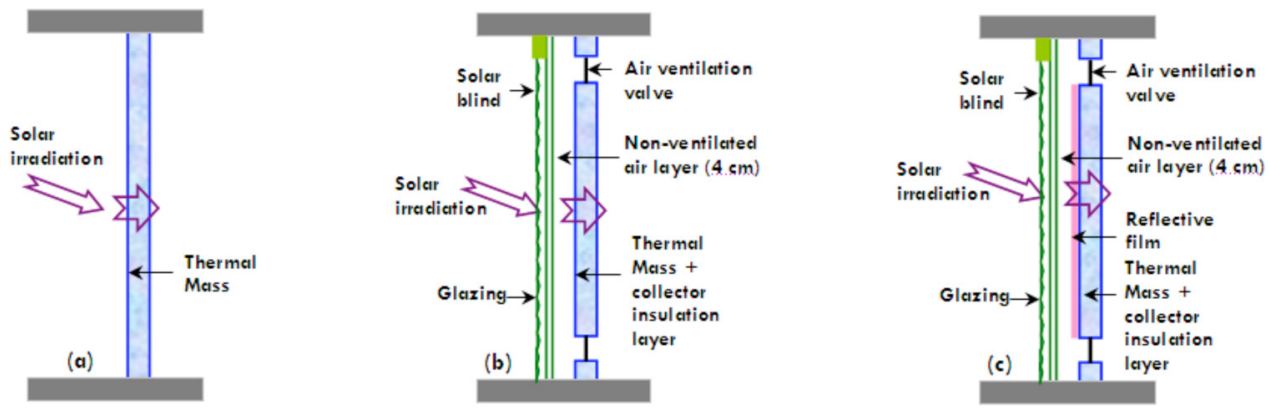

Fig. 3. Trombe wall in overheating periods: (a) ordinary wall; (b) thermal insulation mechanism $\varepsilon=0.9$; (c) thermal insulation with reflective film $\varepsilon=0.05$.

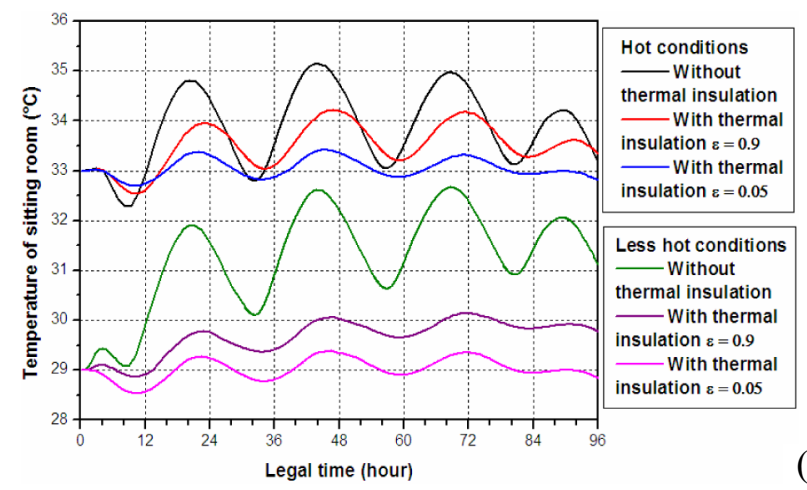

(a)

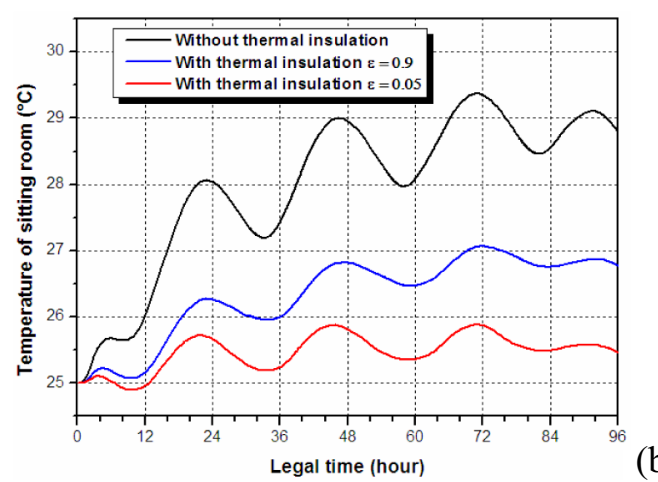

Fig. 4. Predicted air temperature of the sitting room, after (a) and before (b) the thermal storage.

We use every time the optimal thickness $(4 \mathrm{~cm}$ ) of the air layer in the case of thermal insulation, the roof is assumed isolated with $5 \mathrm{~cm}$ of polystyrene $\left(0,036 \mathrm{~W} \mathrm{~m}^{-1} \mathrm{~K}^{-1}\right)$. In summer, it is necessary to think about the overheating problems especially for the months of July and August. The Trombe wall technique is not well adapted to the Saharan regions during this period; we decline our strategy to ensure effective and efficient insulation. The solution is to increase the thermal insulation with closing the orifices (Fig. 3); this aspect can be ensured without any problems since the thickness of the collector insulation layer serves to protect against overheating. Using a low emissivity $(\varepsilon=0.05)$ glass is desirable to further strengthen the thermal resistance of the closed air space. The problem is always solved; we can also close the blinds to still have an additional resistor. The absorber is not useful in this case, it is subsequently very suitable to remove this absorbent surface and replace it with a reflective film. However, in addition to the known formulas that characterize the thermal inertia, we also find precious indices that are the inner surface temperatures of walls and allow to concretely assess the thermal inertia level of such a construction $[11,12]$. That is why we give a capital importance on this parameter that we consider very decisive in determination of the thermal insulation effectiveness by the solar wall technique. The deduced results will depend on these temperatures; incorporation of this aspect will be through the air initial temperature and initial temperatures of inner surfaces of the walls. The latter will describe the thermal state the exterior envelope; we classify the different cases according to the energy storage capacity of the opaque walls in contact with the outside. Then we will be sure to decide that if the initial temperatures are sufficiently high, we can consider that we are in the vicinity of the thermal storage threshold. We will have two capital situations according to the thermal inertia level: one situation after and another before the storage phenomenon (Fig. 4).

Calculated temperatures given in Figure 4a show that the rely of this improvement technique to protect against overheating is useless. Indeed, the inclusion of reflective films avoids a significant portion of the heat. This component provides more stable indoor temperatures and outright eliminates fluctuations.

In Figure 4b, before reaching a high level of thermal inertia we can provide an acceptable comfort by both the consistent incorporation of solar wall and an efficient thermal insulation with eliminating thermal bridging. For a fixed moisture content (water content or moisture content is the quantity of water contained in a material) inside the house $\left(x=410^{-3} \mathrm{~kg}_{\text {water }} / \mathrm{kg}_{\mathrm{dry}}\right.$ air , Fig. 5a), the indoor relative humidity properties will be reversed compared to the temperature. Enhancing the heat insulation corresponds to an increase of the relative humidity, this is logical since the temperature is inversely proportional to the humidity. The influence of the water content (relative humidity) of the interior air on thermal comfort is 


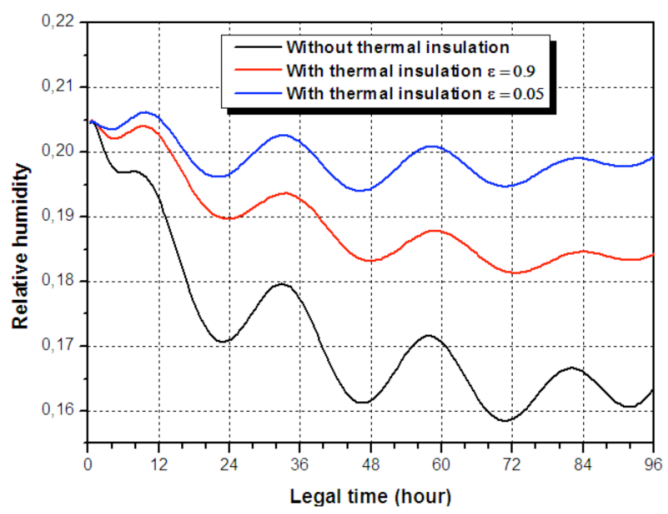

(a)

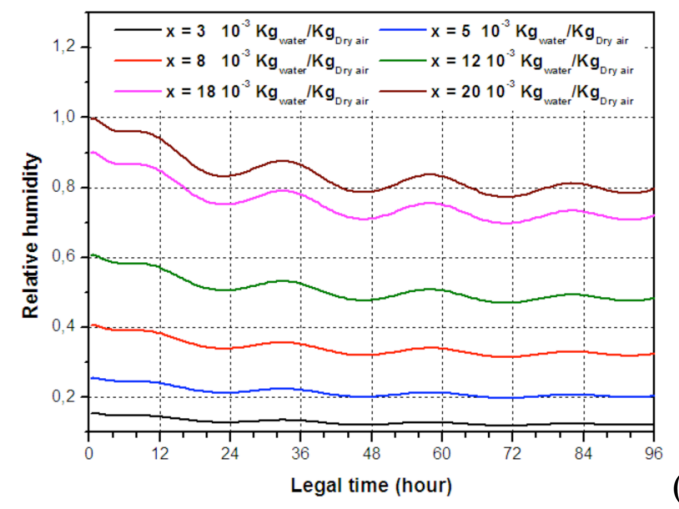

Fig. 5. Predicted relative humidity of the sitting room before the thermal storage as function as: (a) the thermal insulation level; (b) the water content.

sometimes advantageous (Fig. 5b). According to our results, a change from a dry air to a moist air can be compensated by a decrease in temperature in the range of 1.95 to $3.01^{\circ} \mathrm{C}$.

\section{Conclusion}

In summer, the major inconvenience of Trombe wall technique is often encountered under Saharan climate. In this situation, it is mandatory to redirect our strategy to enhance the thermal insulation of facades by inserting reflective films.

In theses environments, for poor compactness of buildings built with heavy materials, we absolutely must avoid the thermal storage phenomenon from the beginning of the hot period in the case where ambient temperatures remain higher compared to the comfort temperature $\left(27^{\circ} \mathrm{C}\right)$. The storage of thermal energy in these circumstances can play a negative role on the desired comfort.

High indoor humidity may result in surface condensation if the temperature of the surface is below the dew point temperature of indoor humidity; this problem is not posed in this application case. The influence of the water content (relative humidity) of the interior air on thermal comfort is sometimes advantageous. There are alternatives to air conditioning, a wet sheet near a conventional ventilator can bring freshness; the reaction that transforms liquid water into vapor absorbs heat.

\section{References}

1. M. Christoph, C. Christoph, E.K. Tilmann, Energy Build. 103, 118 (2015)

2. S.B. Mahmut, B.R. Saffa, Renew. Sustain. Energy Rev. 51, $327(2015)$

3. C. Lamnatou, J. Mondol, D. Chemisana, C. Maurer, Renew. Sustain. Energy Rev. 48, 178 (2015)

4. C. Lamnatou, J. Mondol, D. Chemisana, C. Maurer, Renew. Sustain. Energy Rev. 45, 36 (2015)

5. M. Hamdani, S.M.A. Bekkouche, T. Benouaz, R. Belarbi, M.K. Cherier, Eng. Struc. Tech. 6, 131 (2014)

6. M.A.C. Haddam, S.M.A. Bekkouche, T. Benouaz, M. Hamdani, M.K. Cherier, N. Benamran, Integration of eaves and shading devices for improving the thermal comfort in a multi-zone building, Ther. Sci. 19, Suppl. 2 (2015). DOI:10.2298/TSCI140422117H

7. M. Hamdani, S.M.A. Bekkouche, T. Benouaz, M.K. Cherier, A new modelling approach of a multizone building to assess the influence of building orientation in Saharan climate, Ther. Sci. 19, Suppl. 2 (2015). DOI:10.2298/TSCI131217026H

8. J.B. Saulnier, A. Alexandre, Rev. Gén. Therm. 280,363 (1985)

9. S.M.A. Bekkouche, T. Benouaz, M.K. Cherier, M. Hamdani, M.R. Yaiche, N. Benamrane, Energy Build. 66, 678 (2013)

10. K. Dhalsamant, P.P. Tripathy, S.L. Shrivastava, in ISHMTASME Heat and Mass Transf. Conf. (IIT Kharagpur, India) (2013), Volume 3, p. 28

11. S.M.A. Bekkouche, T. Benouaz, M.K. Cherier, M. Hamdani, M.R. Yaiche, R. Khanniche, Ther. Sci. 17, 349 (2013)

12. S.M.A. Bekkouche, T. Benouaz, M.K. Cherier, M. Hamdani, M.R. Yaiche, N.J. Benamrane, Build. Eng. 1, 42 (2015)

Cite this article as: Sidi Mohammed El Amine Bekkouche, Tayeb Benouaz, Rabéa Kaoulal, Maamar Hamdani, Mohamed Kamel Cherier, Improvement of thermo-aeraulic comfort with integrated solar wall system under Saharan climate, Renew. Energy Environ. Sustain. 1, 9 (2016) 